\title{
Área de Proteção Ambiental Estadual das Águas Vertentes: instrumentos de gestão e potencial turístico
}

Águas Vertentes Environmental Protected Area: management tools and tourist potential

Área de Protección Ambiental Estadual de las Águas Vertentes: instrumentos de gestión y potencial turístico

http://dx.doi.org/10.18472/cvt.18n3.2018.1278

Raquel Faria Scalco 〈raquel.scalco@yahoo.com.br >

Universidade Federal dos Vales do Jequitinhonha e Mucuri (UFVJM), Diamantina, Minas Gerais, MG, Brasil

Daniella Eloi de Souza 〈daniella_eloi@msn.com >

Rede Doctum, Juiz de Fora, Minas Gerais, MG, Brasil

CRONOLOGIA DO PROCESSO EDITORIAL

Recebimento do artigo: 08-maio-2016

Aceite: 30-maio-2018

FORMATO PARA CITAÇÃO DESTE ARTIGO

SCALCO, R. F.; SOUZA, D. E. de. Área de Proteção Ambiental Estadual das Águas Vertentes: instrumentos de gestão e potencial turístico. Caderno Virtual de Turismo. Rio de Janeiro, v. 18, n. 3, p. 22-43, dez. 2018.

REALIZAÇÃO

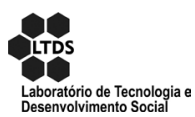

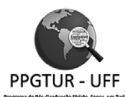

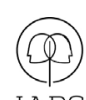

APOIO INSTITUCIONAL

EDIÇÃO

PATROCÍNIO

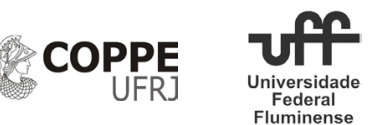

EDITGRA

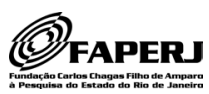




\section{RESUMO}

O conhecimento sobre o potencial turístico de uma unidade de conservação é fundamental para se pensar em estratégias de gestão que orientem o planejamento e as ações para criar alternativas de renda para a comunidade. O presente artigo faz uma análise da oferta turística da Área de Proteção Ambiental Estadual das Águas Vertentes (Apaeav) e de seus instrumentos de gestão, com o objetivo de refletir sobre a realidade e as possibilidades de desenvolvimento da atividade turística. Para alcançar tal proposta, foram utilizados como procedimentos metodológicos: pesquisa bibliográfica; pesquisa de gabinete; análise documental; trabalhos de campo; elaboração de Inventário da Oferta Turística; análise dos dados e elaboração de mapas, tabelas e gráficos. Assim, conclui-se que a principal vocação da Apaeav é para o desenvolvimento do turismo em contato com a natureza, tendo como dificuldades para sua efetiva implementação a precariedade de serviços, equipamentos e infraestrutura. No que se refere à gestão da UC, os maiores desafios estão relacionados à carência de recursos humanos e materiais, bem como o desenvolvimento de ações diferenciadas considerando as características de cada área da APA.

Palavras chave: APA Estadual das Águas Vertentes. Oferta Turística. Gestão.

\section{ABSTRACT}

The knowledge about tourist potential of a protected area is veryimportant to think about management strategies that guide the planning and the actions to create alternative sources of income for the community. This paper makes an analysis of the tourist offer in the Águas Vertentes Environmental Protected Area (APAEAV) and its management tools, with the purpose to think about of the reality and the possibilities of tourism development in this protected area. It was adopted different methodological proceedings: bibliographic research, cabinet research, analysis of documents, field works, making the Inventory of Tourist Offer; data analysis and making maps, tables and graphs. Thus, the conclusion is that main vocation for APAEAV is for the development of tourism in contact with nature, and as difficult to effectively implement are the precariousness of services, equipment and infrastructure. In the management of APAEAV greatest challenges are related to the lack of human and material resources and to development of differentiated actions considering the characteristics of each APA area.

Keywords: APA Estadual das Águas Vertentes. Tourist Supply. Management.

\section{RESUMEN}

El conocimiento acerca el potencial turístico del área protegida es fundamental para reflexionar estrategias de gestión que direccionen la planificación y acciones para la creación de alternativas de ingresos para la comunidad. El artículo hace análisis de la oferta turística del Área de Protección Ambiental Águas Vertentes (APAEAV) y de sus instrumentos de gestión, con el objetivo de reflexionar acerca la realidad y las posibilidades del desarrollo de la actividad turística en esta área protegida. Para lograr la propuesta, fueron adoptados como procedimientos metodológicos: investigación bibliográfica; investigación de gabinete; análisis documental; salidas de campo; elaboración del inventario de la oferta turística; análisis de los datos y elaboración de mapas, tablas y gráficos. Así, se concluye que la principal vocación de la APAEAV es para el desarrollo del turismo en contacto con la naturaleza, intento como dificultades para su efectiva implementación la precariedad de los servicios, equipamientos e infraestructura. En lo que se refiere a la gestión de la APAEAV, los mayores desafíos son la carencia de recursos humanos y materiales e el desarrollo de acciones diferenciadas considerando las características de cada área de la APA.

Palavras clave: APA Estadual de las Aguas Vertentes. Oferta Turística. Gestión. 


\section{INTRODUÇÃO}

A Área de Proteção Ambiental Estadual das Águas Vertentes (Apaeav) é uma Unidade de Conservação (UC) de Uso Sustentável, criada em 21 de janeiro de 1998, por meio do Decreto n 39.309, tendo uma área total de 76.310 ha. Essa UC está localizada na região do Vale do Jequitinhonha e na cadeia do Espinhaço, região que apresenta enorme relevância ambiental e turística e é reconhecida como Reserva da Biosfera pela Unesco. Além disso, possui diversas espécies endêmicas do Cerrado e da Mata Atlântica; é área de nascentes de importantes rios que abastecem a região e possui em seu interior uma gama de atrativos capazes de atrair fluxos turísticos e se configurar como importante fonte de renda para as famílias que ali vivem.

No que se refere à atividade turística, a Apaeav apresenta uma grande variedade de atrativos turísticos, ressaltando principalmente seu aspecto natural, porém, tal potencial ainda é pouco conhecido. Por outro lado, destaca-se a precariedade na infraestrutura e nos serviços turísticos da Apaeav. Apesar dessas dificuldades, a área apresenta alguns distritos onde o turismo já acontece e que possuem melhores estruturas no que se refere aos equipamentos e serviços turísticos para atendimento aos visitantes, podendo-se citar Milho Verde, São Gonçalo do Rio das Pedras e Capivari, pertencentes ao município do Serro.

A ideia deste trabalho surgiu exatamente desse desconhecimento sobre a oferta turística da Apaeav e da hipótese de que existe um grande potencial turístico na região, que pode se configurar como importante fonte de renda para as comunidades presentes nessa UC. Além disso, partiu-se de uma análise dos instrumentos de gestão da Apaeav que apresentam erros, incoerências e fragilidades e que carecem de maior estudo, aprofundamento e propostas de melhorias para que se efetivem em resultados positivos, tanto para a conservação como para o desenvolvimento do turismo na UC.

Têm-se, então, como objetivos do presente artigo fazer uma análise do potencial turístico da APA das Águas Vertentes, bem como de seus instrumentos de gestão, identificando possíveis gargalos, potencialidades e desafios para a gestão da APA e para o desenvolvimento do turismo na UC.

Assim, foram desenvolvidas duas pesquisas paralelas por membros do Grupo Integrado de Pesquisa do Espinhaço - Gipe e que embasam o presente artigo. A primeira delas refere-se a um projeto de iniciação científica desenvolvido por professores e alunos do curso de turismo da UFVJM e que teve como temática a Análise da Oferta Turística da Apaeav. A segunda foi uma dissertação de mestrado do Programa de PósGraduação em Geografia da UFMG, tratando dos aspectos socioambientais e da gestão da APA.

Dessa forma, foram realizadas as seguintes etapas metodológicas: pesquisa bibliográfica, para a formação do arcabouço teórico que sustentou o presente artigo; pesquisa de gabinete, para o levantamento de informações já existentes sobre os municípios pertencentes à Unidade de Conservação, sua oferta turística e seus instrumentos de gestão; análise de documentos relacionados à Gestão da APA, tais como o decreto de criação e os relatórios anuais de atividade; trabalhos de campo, com o intuito de validar dados coletados na pesquisa de gabinete e coletar outros dados necessários; elaboração de Inventário da Oferta Turística, seguindo a metodologia proposta pelo Ministério do Turismo (BRASIL, 2006); análise e processamento dos dados coletados; e elaboração de mapas, tabelas e gráficos.

Com o desenvolvimento das etapas acima descritas, realizadas paralelamente pelas duas pesquisas que subsidiaram o presente artigo, foi produzida uma grande quantidade de informação sólida e fidedigna sobre a Apaeav, tanto no que se refere ao seu potencial turístico como em seus aspectos socioambientais 
e de gestão da UC. Destaca-se que a inexistência de tais informações sempre foi um entrave para a gestão e para o desenvolvimento de muitas ações, sendo esses estudos inclusive demandados pelo próprio órgão gestor da UC. Dessa forma, tais pesquisas contribuem para que os objetivos de criação da APA sejam mais facilmente alcançados, servindo de subsídio teórico para o planejamento e a gestão da UC e contribuindo para que a atividade turística se configure como uma possibilidade para o desenvolvimento econômico e social da área abrangida pela Unidade de Conservação.

\section{METODOLOGIA}

O presente artigo baseou-se em duas pesquisas desenvolvidas por membros do Gipe e que tiveram como objeto de estudo a APA Estadual das Águas Vertentes. Tais pesquisas possuem caráter qualitativo e se propõem a fazer uma análise descritiva e exploratória da Apaeav. A pesquisa qualitativa, de acordo com Lakatos e Marconi (2007), preocupa-se em analisar e interpretar aspectos mais profundos, descrevendo a complexidade do comportamento humano ou do fenômeno analisado. Já a pesquisa descritiva, de acordo com Gil (1994), tem como objetivo a descrição das características de determinada população ou fenômeno, ou o estabelecimento de relações entre variáveis. Por fim, a pesquisa exploratória é realizada quando existe pouco ou nenhum material sobre o objeto analisado e o produto final desse processo é um problema mais esclarecido, passível de investigação mediante procedimentos sistematizados (GIL, 1994).

A primeira pesquisa que subsidiou este artigo refere-se a um projeto de iniciação científica que contou com a participação de três professores coordenadores do curso de Turismo da UFVJM e com nove alunos bolsistas e voluntários do curso de Turismo, Geografia e Engenharia Florestal da UFVJM. Este projeto foi desenvolvido entre abril de 2013 e outubro de 2014 e teve como temática a Análise da Oferta Turística da Apaeav.

A segunda pesquisa trata-se de uma dissertação de mestrado do Programa de Pós-Graduação em Geografia da UFMG, desenvolvida entre janeiro de 2013 e agosto de 2014, que teve como temática os aspectos socioambientais e a gestão da APA Estadual das Águas Vertentes.

Assim, o presente artigo é uma compilação de dados obtidos por meio desses estudos de caso sobre a Apaeav, tendo sua sustentação na pesquisa bibliográfica, na pesquisa documental e em trabalhos de campo, implicando a coleta de dados primários e secundários.

A primeira etapa tratou-se de uma pesquisa bibliográfica para a formação do arcabouço teórico que sustentou a presente pesquisa, sendo estudados os seguintes temas: turismo, Unidades de Conservação, instrumentos de gestão de UCs e estudo da oferta turística.

Em seguida, foi realizada uma pesquisa de gabinete para levantamento de informações sobre a Apaeav, sendo coletados documentos nos seguintes órgãos: Prefeituras Municipais dos municípios pertencentes à Apaeav, Instituto Estrada Real, Fundação João Pinheiro, Circuito dos Diamantes, Instituto Estadual de Florestas, UFVJM e UFMG.

Foi então realizada uma análise de tais documentais com o objetivo de compreender os instrumentos que subsidiam a gestão da UC, sendo analisados o Decreto de criação da Apaeav e os Relatórios Anuais de Atividade (2012 e 2013). Além disso, foram analisados os dados dos inventários da oferta turística dos municípios abrangidos pela APA. 
Posteriormente, seguiu-se para os trabalhos de campo, com o intuito de validar dados coletados na pesquisa de gabinete e coletar outros dados necessários. Essa etapa ocorreu em todos os municípios pertencentes à Apaeav, possibilitando a elaboração do Inventário da Oferta Turística desta, seguindo-se a metodologia proposta pelo Ministério do Turismo (BRASIL, 2006). Nos trabalhos de campo, além do preenchimento dos formulários, foram feitos registros fotográficos e marcação de pontos e trilhas com o uso do GPS.

Em seguida, foram elaborados mapas, tabelas e gráficos, tendo por base o material coletado em campo e nas pesquisas de gabinete e documental, possibilitando uma sistematização dos dados e melhor entendimento e visualização das informações coletadas.

Por fim, foi feita a análise quantitativa e qualitativa da oferta turística da APA, bem como sobre os instrumentos de gestão utilizados, possibilitando um entendimento sobre o potencial turístico da UC e sobre os gargalos e desafios a serem enfrentados pelo órgão gestor para que o turismo se torne uma atividade econômica importante para a região.

\section{REFERENCIAL TEÓRICO}

\section{ECOTURISMO}

O turismo possui diversos segmentos, entre eles o ecoturismo. Com isso, a prática dessa atividade está diretamente ligada ao meio natural, proporcionando um contato maior entre o homem e a natureza e, ao mesmo tempo, promovendo a conscientização ambiental.

O ecoturismo surgiu no Brasil como uma proposta de contemplação e conservação da natureza. Os debates sobre a necessidade de conservação do meio ambiente atingiram a atividade turística e inseriram uma nova maneira de vivenciar e usufruir dos recursos naturais, vistos como propícios para um modelo de turismo mais responsável.

Esse segmento pode proporcionar experiências enriquecedoras e contribui para a conservação dos ecossistemas, ao mesmo tempo em que estabelece uma situação de ganhos para todos os interessados: se a base de recursos é protegida, os benefícios econômicos associados ao seu uso serão sustentáveis (BRASIL, 2010, p. 13).

Segundo diversas instituições e operadores especializados, esse tipo de turismo vem apresentando um crescimento contínuo no mundo e no Brasil, crescimento este inclusive acima da média de outros segmentos da atividade turística.

Para a Embratur e o Ministério do Meio Ambiente, o ecoturismo:

[...] é um segmento da atividade turística que utiliza, de forma sustentável, o patrimônio natural e cultural, incentiva sua conservação e busca a formação de uma consciência ambientalista por meio da interpretação do ambiente, promovendo o bem-estar das populações (BRASIL, 2010, p. 16).

Dessa forma, o ecoturismo é uma atividade realizada em meio natural que visa o aproveitamento do meio ambiente como local de lazer, concomitantemente com a valorização da comunidade local, pautado na busca pelo desenvolvimento sustentável em contraponto ao turismo de massa (FONTOURA; 
SILVEIRA, 2008). Ainda pode ser considerado como uma forma de atividade menos predatória, que visa à conservação da natureza e se constitui como uma alternativa para o desenvolvimento socioeconômico de localidades menos favorecidas (RODRIGUES, 1999 apud FONTOURA; SILVEIRA, 2008).

Para o Ministério do Turismo (2010, p.17),

Esse tipo de turismo pressupõe atividades que promovam a reflexão e a integração homem e ambiente, em uma inter-relação vivencial com o ecossistema, com os costumes e a história local. Deve ser planejado e orientado visando o envolvimento do turista nas questões relacionadas à conservação dos recursos que se constituem patrimônio (BRASIL, 2010, p.17).

Um dos principais locais onde este segmento do turismo se desenvolve é nas Unidades de Conservação, visando proporcionar ao visitante um contato próximo com o meio natural preservado e ao mesmo tempo contribuir para que os objetivos de conservação das UCs sejam atingidos.

\section{UNIDADES DE CONSERVAÇÃO}

O marco inicial do surgimento de áreas protegidas está relacionado à criação do Parque Nacional de Yellowstone, nos Estados Unidos, em 1872, criado como espaço de conservação e preservação da natureza, e que instigou outros países a adotarem o mesmo procedimento.

No Brasil, especificamente a partir de 1937, começaram a surgir os primeiros parques nacionais, mas somente foram regulamentados em 2000, com a criação da Lei ${ }^{\circ}$ 9.985, que institui o Sistema Nacional de Unidades de Conservação (Snuc). Essa lei prevê o manejo e a gestão de áreas protegidas nas diversas escalas.

O Snuc define Unidade de Conservação da seguinte forma:

[...] espaço territorial e seus recursos ambientais, incluindo as águas jurisdicionais, com características naturais relevantes, legalmente instituídos pelo Poder Público, com objetivos de conservação e limites definidos, sob regime especial de administração, ao qual se aplicam garantias adequadas de proteção. (BRASIL, 2000, art. $2^{\circ}$ ).

As Unidades de Conservação integrantes do Snuc dividem-se em dois grandes grupos, com características específicas: grupo de Unidades de Conservação de Proteção Integral e grupo de Unidades de Conservação de Uso Sustentável. Esses dois grupos são subdivididos em categorias específicas, nas quais são proibidas e/ou permitidas determinadas atividades.

São classificadas como Unidades de Conservação de Proteção Integral: a Estação Ecológica, a Reserva Biológica, o Parque Nacional, o Monumento Natural e o Refúgio de Vida Silvestre. São consideradas Unidades de Conservação de Uso Sustentável: a Área de Proteção Ambiental (APA), Área de Relevante Interesse Ecológico, Floresta Nacional, Reserva Extrativista, Reserva de Fauna, Reserva de Desenvolvimento Sustentável e Reserva Particular do Patrimônio Natural.

Entre as categorias de Unidades de Conservação especificadas acima, a área de estudo em questão neste trabalho é uma Unidade de Conservação de uso sustentável, mais especificamente uma Área de Proteção Ambiental (APA).

Segundo o Snuc (BRASIL, 2000, art. $7^{\circ}$ ), o "objetivo básico das Unidades de Uso Sustentável é compatibilizar a conservação da natureza com o uso sustentável de parcela dos seus recursos naturais". 
Ainda segundo o Snuc, a Área de Proteção Ambiental pode ser definida da seguinte forma:

É uma área em geral extensa, com certo grau de ocupação humana, dotada de atributos abióticos, bióticos, estéticos ou culturais especialmente importantes para a qualidade de vida e o bem-estar das populações humanas, e tem como objetivos básicos proteger a diversidade biológica, disciplinar o processo de ocupação e assegurar a sustentabilidade do uso dos recursos naturais. (BRASIL, Lei n 9.985/2000, art. 15)

Ao mesmo tempo em que esse tipo de UC é menos restritivo em relação ao uso dos recursos naturais, a sua criação muitas vezes limita várias atividades tradicionalmente desenvolvidas pelas comunidades. Isso se deve não só às normas de cada Unidade de Conservação, mas também pela presença do órgão gestor e consequente aumento da fiscalização ambiental no local.

O Snuc (BRASIL, 2000), para assegurar a conservação da diversidade biológica e dos ecossistemas, estabeleceu que as UC devem elaborar um plano de manejo, quer dizer, um documento técnico mediante o qual, com fundamento nos objetivos gerais de uma Unidade de Conservação, estabelece o seu zoneamento e as normas que devem orientar o uso da área e o manejo dos recursos naturais, inclusive a implantação das estruturas físicas necessárias à gestão da unidade.

Para que uma UC possa ser utilizada para fins turísticos, faz-se necessária a elaboração de um plano de manejo que inclua medidas para promover a integração da UC à vida econômica e social das comunidades vizinhas, visando subsidiar o planejamento e a gestão da área. Dessa forma, é possível identificar áreas e atividades que devem ser incentivadas com o objetivo de trazer melhorias para as comunidades locais.

O Plano de Manejo é o documento oficial de planejamento das Unidades de Conservação no Brasil. Esse documento deve conter o diagnóstico da UC, assim como propostas de ações a serem implementadas. De acordo com a Lei 9.985/2000, que instituiu o Snuc, o Plano de Manejo é definido como:

Documento técnico mediante o qual, com fundamento nos objetivos gerais de uma Unidade de Conservação, se estabelece o seu zoneamento e as normas que devem presidir o uso da área e o manejo dos recursos naturais, inclusive a implantação das estruturas físicas necessárias à gestão da unidade. (BRASIL, 2000, art. $2^{\circ}$ )

Assim, para que o ecoturismo e/ou qualquer outro segmento turístico seja desenvolvido corretamente, faz-se necessário um extenso trabalho de planejamento turístico, visando garantir que os impactos positivos da atividade sejam superiores aos impactos negativos. Esse planejamento torna-se ainda mais importante quando o local é protegido por meio de uma Unidade de Conservação. Nesse sentido, uma das etapas desse planejamento deve ser o estudo da oferta turística do local.

\section{ESTUDO DA OFERTA TURÍSTICA}

A oferta turística é considerada como um conjunto de bens/serviços que estão à disposição do turista, ou seja, tudo aquilo que pode ser oferecido aos turistas. Ela deve ser atraente e ter qualidade, a fim de que os visitantes fiquem satisfeitos, retornem e indiquem o destino a outras pessoas.

Inclui-se entre os elementos constituintes da oferta turística os atrativos turísticos, os serviços e equipamentos turísticos, e toda a infraestrutura de apoio ao turismo.

Para Beni (2006, p. 169):

Pode-se definir a oferta turística básica como um conjunto de equipamentos, bens e serviços de alojamentos, de alimentação, recreação e lazer, de caráter artístico, cultural, social ou de outros tipos, capaz de atrair e assentar numa 
determinada região, durante um período determinado de tempo, um público visitante. Em suma, a oferta turística pode ser concebida como o conjunto dos recursos naturais e culturais que, em sua essência, constituem a matéria-prima da atividade turística.

As categorias que compõem a oferta turística, segundo o Manual de Inventariação da Oferta Turística produzido pelo Ministério do Turismo (BRASIL, 2006), são: infraestrutura de apoio ao turismo; serviços e equipamentos turísticos; e atrativos turísticos. De acordo com o manual do Ministério do Turismo, essas categorias são definidas da seguinte forma:

INFRAESTRUTURA DE APOIO AO TURISMO: Conjunto de obras, de estruturas e serviços que proporciona boas condições de vida para a comunidade e dá base para o desenvolvimento da atividade turística: sistemas de transporte, energia elétrica, serviço de abastecimento de água, arruamento, sistema de comunicação, sistema educacional, etc.

SERVIÇOS E EQUIPAMENTOS TURÍSTICOS: Conjunto de serviços, edificações e instalações indispensáveis ao desenvolvimento da atividade turística e que existem em função desta. Compreendem os serviços e os equipamentos de hospedagem, alimentação, agenciamento, transportes, área de eventos, de lazer e entretenimento, etc.

ATRATIVOS TURÍSTICOS: Locais, objetos, equipamentos, pessoas, fenômenos, eventos ou manifestações capazes de motivar o deslocamento de pessoas para conhecê-los. (BRASIL, 2006, p. 10).

Ao processo de levantamento dos dados referentes à oferta turística de um determinado local, dáse o nome de Inventário da Oferta Turística, definido como "Processo de levantamento, identificação e registro dos Atrativos Turísticos, dos Serviços e Equipamentos Turísticos e da Infraestrutura de apoio ao Turismo como instrumento-base de informações para fins de planejamento e gestão da atividade turística" (BRASIL, 2006, p. 10).

A metodologia proposta pelo Ministério do Turismo para Inventariação da Oferta Turística é a forma mais amplamente aceita de se obter todas as informações sobre a oferta turística de determinado local (BRASIL, 2006, p. 10).

\section{A APA DAS ÁGUAS VERTENTES: ASPECTOS HISTÓRICOS E GEOGRÁFICOS}

A Apaeav está localizada a 290 quilômetros de Belo Horizonte/MG, na microrregião Alto Jequitinhonha e se localiza entre as latitudes $18^{\circ} 10^{\prime} \mathrm{S}$ e $18^{\circ} 35^{\prime} \mathrm{S}$ e entre as longitudes $43^{\circ} 35^{\prime} \mathrm{W}$ e $43^{\circ} 10^{\prime} \mathrm{W}$. Essa UC abrange parte dos municípios de Serro, Diamantina, Couto de Magalhães de Minas, Felício dos Santos, Rio Vermelho, Serra Azul de Minas e de Santo Antônio do Itambé, como pode ser visualizado no mapa da Figura 1, abaixo. 


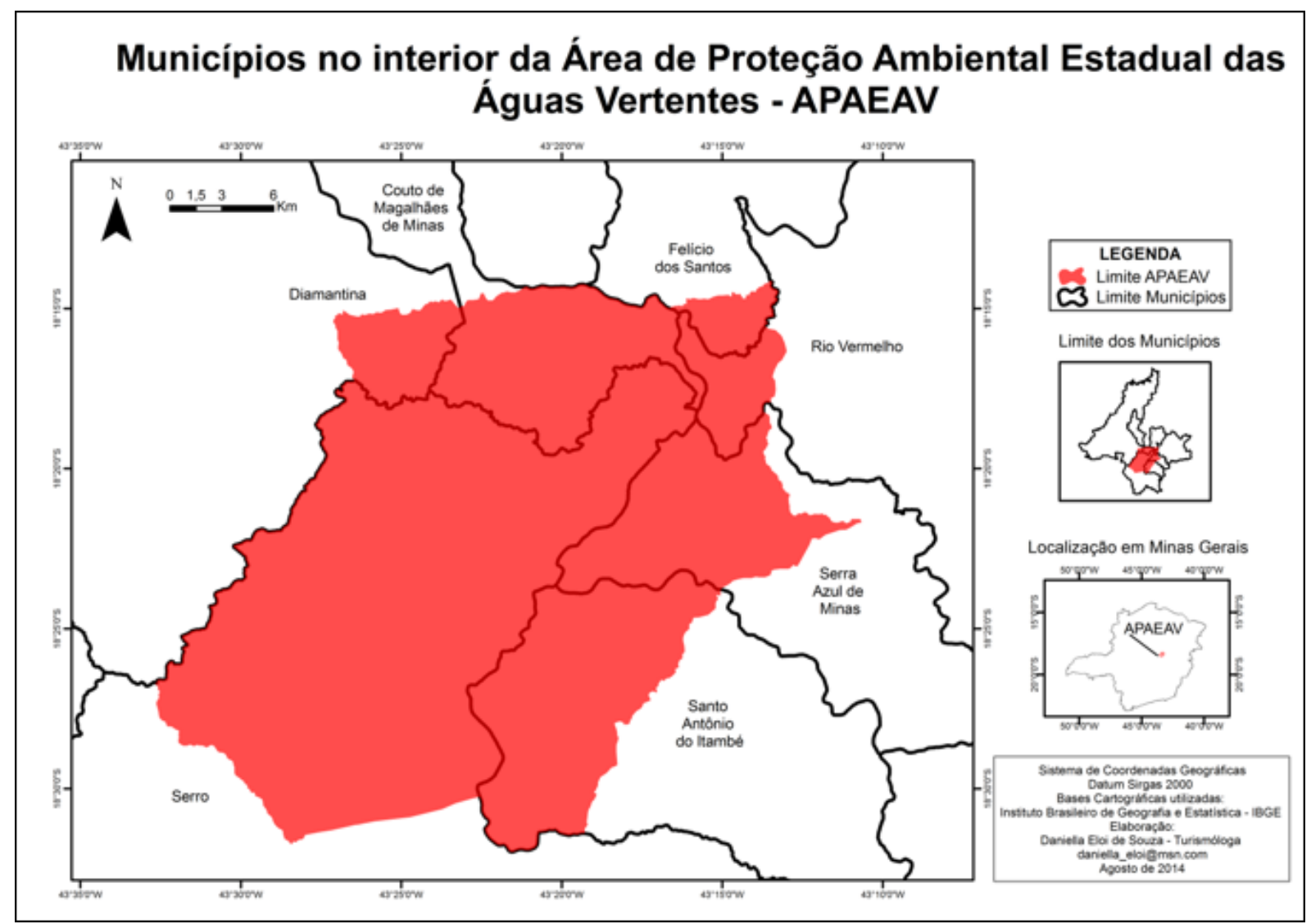

Figura 1 - Mapa dos municípios inseridos na Apaeav.

Fonte: Souza, 2014.

A Apaeav está inserida na Serra do Espinhaço Meridional, o segmento sul da Serra do Espinhaço, que ocupa áreas das regiões Sudeste e Central do Brasil, estendendo-se por cerca de $1.200 \mathrm{~km}$ na direção Norte-Sul, desde a porção central do estado de Minas Gerais até o extremo norte da Bahia (ABREU et al., 2006).

Considerando a Serra do Espinhaço de uma forma geral, de acordo com Comig/IGC (1997 apud GONTIJO, 2008), o clima regional é subtropical quente, com microclimas diversos relacionados a fatores topográficos. A temperatura média anual está em torno de $18^{\circ} \mathrm{C}$ a $19^{\circ} \mathrm{C}$ e a precipitação anual é de 850 $\mathrm{mm}$ a $1.400 \mathrm{~mm}$.

As características peculiares do relevo da Serra do Espinhaço são determinadas, sobretudo, pela natureza quartzítica das rochas que constituem essa serra, rochas que promovem a formação de solos rasos, arenosos e pobres em nutrientes (ABREU et al., 2005).

Destaca-se, ainda, que a Apaeav está inserida no Mosaico de Áreas Protegidas do Espinhaço: Alto Jequitinhonha - Serra do Cabral e que em seu interior e entorno estão localizadas outras importantes Unidades de Conservação, como o Parque Estadual do Pico do Itambé (Pepi) e o Monumento Natural Várzea do Lajeado e Serra do Raio (Monat), no interior da Apaeav; e os Parques Estaduais do Rio Preto (Perp) e do Biribiri (Pebi), que se encontram em seu entorno. Esse fato ressalta a importância ambiental da região e contribui para a existência de uma paisagem mais exuberante e preservada. A presença do 
Mosaico de Áreas Protegidas e das UCs próximas à Apaeav pode ser visualizada no mapa da Figura 2, abaixo.

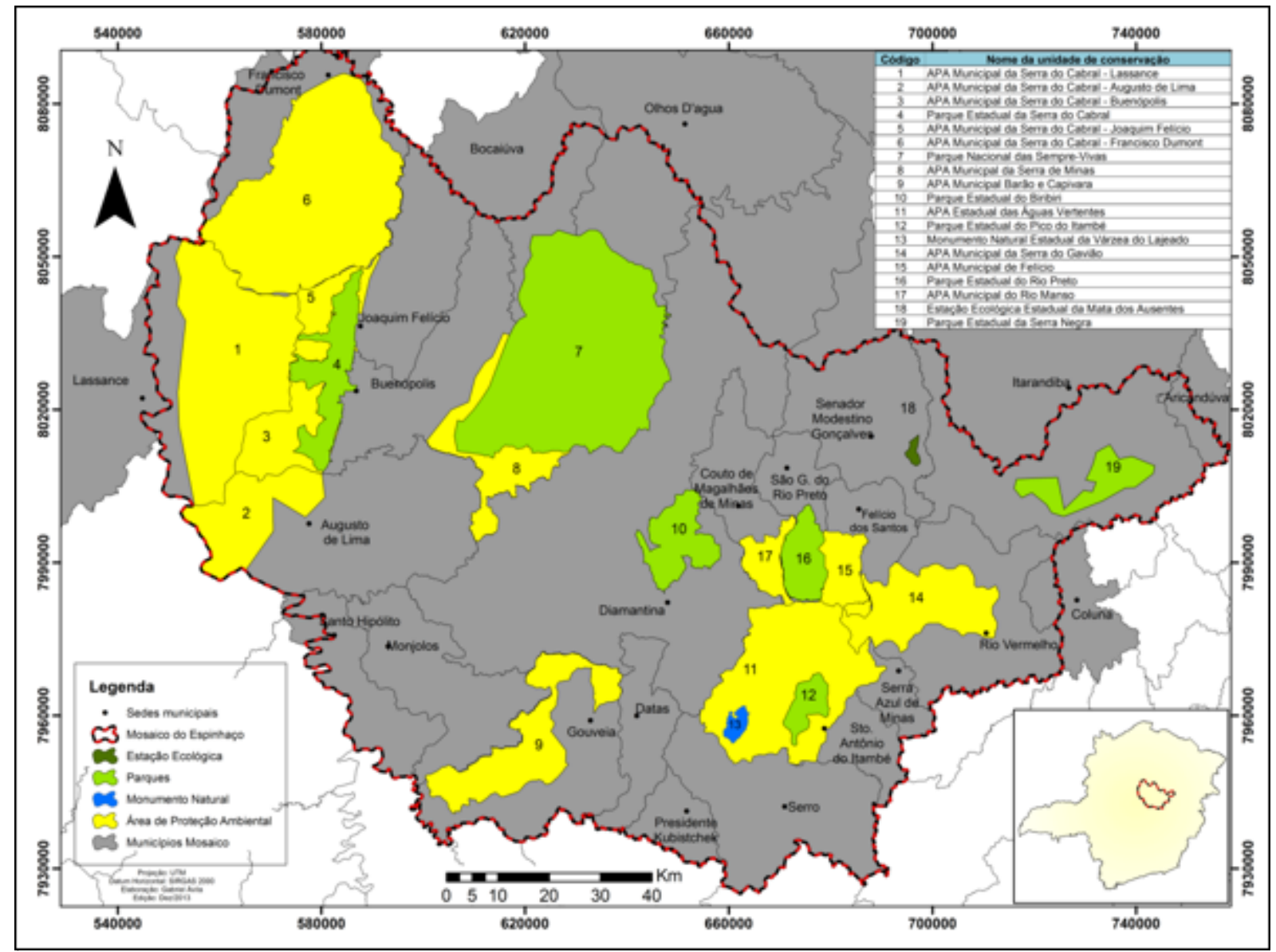

\section{Figura 2 - Mapa do Mosaico de Áreas Protegidas do Espinhaço: Alto Jequitinhonha e Serra do Cabral.}

Fonte: Ávila, 2014.

A altitude na Apaeav varia de 724 m a 2002 m e sua elevação máxima se dá no Pico do Itambé, com $2.002 \mathrm{~m}$ de altitude, ponto mais alto da Serra do Espinhaço, situado na divisa entre os municípios de Santo Antônio do Itambé, Serra Azul de Minas e Serro.

Na Apaeav, duas bacias hidrográficas principais estão presentes: a do Rio Jequitinhonha e a do Rio Doce, sendo que a linha divisória dessas duas bacias situa-se a noroeste da cidade do Serro e estende-se para a Serra do Itambé e Serra Negra, sendo que parte dessa divisão ocorre dentro dos limites da Apaeav (FRAGA et al., 2005).

De acordo com Souza (2014), a Apaeav possui importantes afluentes da sub-bacia do Rio Doce: o Rio do Peixe, o Rio Guanhães e o Rio Vermelho. Já o Rio Jequitinhonha representa o limite sudeste da Apaeav e sua principal nascente está localizada no distrito de Três Barras, no Serro, dentro da Unidade de Conservação. 
De acordo com Fraga et al. (2005), na região da Mata dos Crioulos, os Ribeirões Capivari e da Pomba e o Córrego das Pindaíbas, que têm nascentes nos campos de altitude da Chapada do Couto, encontram-se com o Jequitinhonha. Na Ponte do Acaba Mundo, restos de canais construídos por garimpeiros encontramse ainda preservados e as margens do Rio Jequitinhonha mostram-se arenosas pelo assoreamento causado por essa atividade (FRAGA et al., 2005). É nesse cenário que o imponente Córrego do Soberbo, conhecido popularmente como Jequitinhonha Preto, encontra-se com o Jequitinhonha - ali chamado Jequitinhonha Branco. Outras drenagens presentes na Apaeav são descritas no trabalho por Fraga et al. (2005) e Souza (2014) e demonstram a importância hídrica dessa Unidade de Conservação, o que justifica a referência a esse recurso natural na denominação dessa UC.

$\mathrm{Na}$ Apaeav estão presentes as vegetações típicas do Cerrado, de Campo Rupestre e da Floresta Estacional Semidecidual (SOUZA, 2014). A localização na faixa de transição de biomas e bacias condiciona à região significativa biodiversidade de espécies e presença de espécies de fauna e flora endêmicas desse território.

Souza (2014) aponta que a Apaeav possui baixa densidade demográfica, mas que em praticamente todo o território há a presença de uma pequena comunidade. Essa autora identificou 59 localidades em todo o território.

A região, que começou a ser povoada no início do século XVII, quando os colonos fundaram as vilas ao longo dos rios, foi palco da exploração de minério, principalmente diamante e ouro. Porém, essa extração não garantiu o desenvolvimento da região. A mesma autora afirma que os moradores dessa UC são hoje, em sua maioria, de baixa renda e pertencentes à classe social $\mathrm{E}$.

Hoje, o sustento familiar dos moradores locais se dá principalmente pelo complemento de mais de uma atividade econômica: produção rural, comércio, prestação de serviços, venda de produtos artesanais e programas assistencialistas. Ressalta-se que, na região, a agricultura familiar é, além de uma atividade econômica, também, um ofício tipicamente cultural.

$\mathrm{Na}$ Unidade de Conservação estão localizadas cinco comunidades quilombolas reconhecidas pela Fundação Cultural Palmares, são elas: Mata dos Crioulos, Ausente, Queimadas, Santa Cruz e Vila Nova. Essas comunidades se autodeclararam como remanescentes de quilombos, porém, ainda não tiveram seus territórios demarcados, processo este que se encontra em andamento.

\section{RESULTADOS E DISCUSSÕES}

\section{ANÁLISE DOS INSTRUMENTOS DE GESTÃO DA APA DAS ÁGUAS VERTENTES}

A Área de Proteção Ambiental Estadual das Águas Vertentes foi criada em 1998, mas recebeu sua primeira equipe gestora pelo Estado, especificamente para trabalhos nessa Unidade de Conservação, em 2008. Essa área protegida não possui Plano de Manejo, mas possui outros instrumentos de gestão que são base para a atuação da equipe responsável, como: o decreto de criação da unidade, documentos relativos ao Conselho Gestor, Planos de Ação e Relatórios Anuais de Atividades.

O Plano de Manejo da APA está em processo de elaboração pela empresa licitada STCP Engenharia e Projetos LTDA, de Curitiba/PR. Em função da ausência desse documento, o principal instrumento que 
vem sendo utilizado para embasar as ações da unidade são os Planos de Ação Anuais, que são documentos internos. Esses planos são elaborados pela própria equipe gestora e estabelecem metas, objetivos e meios para serem alcançados anualmente. Além destes, a equipe gestora elabora os Relatórios Anuais de Atividades, que são também documentos internos, mas que são divulgados pela equipe da UC ao público em geral, pois são, além de um instrumento de monitoramento das ações realizadas, uma forma de prestação de contas das ações desenvolvidas. Além desses documentos, o decreto de criação da UC dispõe sobre os objetivos e ações a serem realizadas na Apaeav e, portanto, é oficialmente o documento mais importante dessa área protegida.

Como os Planos de Ação não são divulgados publicamente, fez-se uma análise do decreto de criação e dos relatórios anuais de atividades buscando-se identificar quais princípios de gestão e ações desenvolvidas que têm relação com a atividade turística na UC, com objetivo de verificar se as ações têm correspondido ao que foi proposto/pensado para a Unidade de Conservação no que diz respeito ao turismo.

Em seu Artigo $2^{\circ}$, o decreto apresenta os objetivos de criação da unidade, segundo o qual se tem como objetivo geral da Apaeav: "garantir a conservação do conjunto paisagístico e da cultura regionais". É interessante elucidar a menção à proteção da paisagem. Essa importância dada à paisagem e também à cultura regional, além de ter relação direta com a manutenção dos recursos naturais, está relacionada à manutenção das características visuais do ambiente e práticas dos moradores.

Nesse aspecto, os objetivos da Apaeav podem ser relacionados aos preceitos da categoria da Unesco V - Paisagem protegida. Porém, para Souza (2014), essa categoria faz menção à intrínseca existência de aspectos tradicionais dos moradores, o que, no olhar da pesquisadora, não condiz com as características da Apaeav em sua totalidade.

Por outro lado, esse anseio do objetivo geral da Apaeav pode também ser relacionado com os parques naturais alemães, os quais foram utilizados como base para criação das APAs no Brasil (SCALCO, 2009). Nessa categoria, assim como na Apaeav, a manutenção de aspectos culturais e paisagísticos possibilita seu usufruto para fins recreacionais, como a atividade turística, que pode ser uma das atividades econômicas de desenvolvimento e melhoria da qualidade de vida local, se bem planejada, compatibilizando os benefícios econômicos e a proteção do meio ambiente, por sua vez, como nos parques franceses (CABRAL; SOUZA, 2005).

Além do objetivo geral, o artigo $2^{\circ}$. do decreto de criação da Apaeav apresenta os objetivos específicos, e o artigo $5^{\circ}$., algumas medidas a serem implementadas na Unidade de Conservação. Em essência, esses textos representam os pilares da criação dessa área protegida na forma de intervenções de gestão a serem implementadas.

Entre os cinco objetivos específicos de criação da Apaeav, dois tem relação com a atividade turística. Analisando os Relatórios Anuais de Atividades, foram identificadas as seguintes ações compatíveis com esses objetivos, conforme Quadro 1, a seguir. 


\section{Quadro 1 - Relação entre Objetivos da Apaeav e ações de gestão, relacionados ao turismo}

\begin{tabular}{|l|l|}
\hline \multicolumn{1}{|c|}{ Objetivo do decreto da Apaeav } & \multicolumn{1}{c|}{ Ações compatíveis } \\
\hline $\begin{array}{l}\text { IV - Promover atividades } \\
\text { econômicas compatíveis com a } \\
\text { qualidade ambiental desejável } \\
\text { para a região }\end{array}$ & $\begin{array}{l}\text { VI - Reunião com produtores de banana, Reuniões para } \\
\text { ordenamento da atividade turística }\end{array}$ \\
\hline $\begin{array}{l}\text { V- Promover, desenvolver e } \\
\text { ordenar o ecoturismo regional. }\end{array}$ & $\begin{array}{l}\text { V- Blitz Educativa em Feriados, Curso Turismo de Base Local, } \\
\text { Pesquisa Perfil do Turista em Feriados, Sinalizatur, Identificação } \\
\text { de atrativos, Código de Posturas de Milho Verde, Capacitação } \\
\text { de Guias em Milho Verde, Encontro Cultural Ambiental de Milho } \\
\text { Verde e Levantamento da Oferta Turística da Apaeav. }\end{array}$ \\
\hline
\end{tabular}

Fonte: Elaboração própria a partir de dados de MINAS GERAIS (1998); SOUZA (2013); SOUZA (2014); FERNANDES et al. (2014).

A atividade turística tem um apelo econômico e social muito grande na região. Antes mesmo da criação da Apaeav, já era uma atividade localmente desenvolvida e, por isso, esse fenômeno aparece como um dos cinco objetivos da unidade, na forma do segmento de ecoturismo, previsto pelo objetivo V; e, além disso, diante de um planejamento dessa atividade, pode ser visto como um dos caminhos para alcance do objetivo IV, que é a promoção de "atividades econômicas compatíveis com a qualidade ambiental".

Os relatórios anuais de atividade não apresentam projetos consolidados de promoção de atividades econômicas para a região. Em consonância ao objetivo IV da unidade, que relaciona-se a essa questão, conforme Quadro 1, foi identificado o apoio ao projeto de produção de banana. Ressalta-se que esse tipo de projeto é potencial para a região, uma vez que não é uma atividade de alto custo, favorece a utilização do produto para consumo, contribuindo para a qualidade de vida dos moradores, mas, também, para sua utilização para manufatura de produtos alimentícios, que podem ser comercializados aos turistas que visitam a região.

Além disso, os Relatórios fazem referência a reuniões para o ordenamento da atividade turística. Porém, não apresentam projetos consolidados nesse sentido.

Com relação ao objetivo $\mathrm{V}$, que prevê o desenvolvimento do ecoturismo na unidade, foram identificadas diversas ações relacionadas à sensibilização, planejamento, capacitação, eventos e pesquisa. Essa diversidade de atividades sinaliza positivamente para uma preocupação da equipe gestora no atendimento a esse objetivo. Porém, nota-se a predominância de atividades pontuais, que ocorrem em dias específicos, como feriados, e também percebe-se que a maioria dessas ações concentra-se em apenas uma região da Apaeav, comunidade de Milho Verde e seu entorno.

Para Souza (2014), a ausência do zoneamento prejudica especialmente o alcance dos objetivos I e II da Apaeav, os quais dizem respeito à proteção e recuperação direta do patrimônio natural. Porém, um olhar mais atento nos mostra que até mesmo para o alcance dos demais objetivos, como o VI e V, a inexistência desse instrumento de gestão é um gargalo, pois a maioria das ações está concentrada em uma determinada região da Apaeav. Além disso, com o zoneamento, seria possível definir áreas preferenciais para a elaboração de determinados projetos de desenvolvimento do turismo.

O ecoturismo é apenas um dos segmentos do turismo que pode ser desenvolvido nas comunidades. Como essa área protegida não tem somente como objetivo a preservação dos recursos naturais, mas também 
o desenvolvimento de atividades econômicas, torna-se necessário ampliar o leque de possibilidades de fomento a outros segmentos dessa atividade (como o turismo rural, o turismo cultural, o turismo religioso, entre outros). Alguns desses já ocorrem em algumas localidades e podem ser apoiados pela gestão da UC.

Todavia, é inegável o potencial do ecoturismo na região e é perceptível que esse potencial ainda é muito pouco explorado. Embora haja um número expressivo de turistas que visitam a Apaeav em busca do patrimônio natural, em especial nos distritos de Milho Verde e São Gonçalo do Rio das Pedras, essa visitação nem sempre pode ser considerada como ecoturismo, de acordo com conceitos oficiais da atividade, os quais estão mais relacionados ao respeito, admiração e contemplação da paisagem e dos aspectos naturais (SOUZA, 2013).

Não foram identificadas nos Relatórios Anuais de Atividades (analisados nesta pesquisa, até 2014) outras ações da equipe gestora que condizem com os objetivos específicos da Apaeav instituídos pelo seu decreto de criação e que sejam relacionadas à atividade turística.

Cabe destacar que Souza (2014) ressalta que o grande número de combate a incêndios florestais ocorridos na unidade absorve muito tempo dos funcionários, dificultando o desenvolvimento de outras ações, o que nos parece ser um empecilho para a concretização de projetos mais consolidados.

\section{ANÁLISE DA OFERTA TURÍSTICA DA APA ESTADUAL DAS ÁGUAS VERTENTES}

Para que a atividade turística se desenvolva de forma ordenada em um determinado local, é necessário que haja um planejamento dessa atividade e a primeira etapa desse processo é o diagnóstico, que tem como base o Estudo da Oferta Turística. A este documento contendo as características quantitativas e qualitativas da Oferta Turística de determinado local dá-se o nome de Inventário da Oferta Turística.

As categorias que compõem a oferta turística são: infraestrutura de apoio ao turismo; serviços e equipamentos turísticos; e atrativos turísticos, conforme conceitos apresentados no referencial teórico.

A partir das pesquisas realizadas, foram identificados aspectos quantitativos e qualitativos referentes à oferta turística da APA das Águas Vertentes. Foi diagnosticado o enorme potencial turístico da área, apresentando 97 atrativos turísticos presentes em todos os municípios abrangidos pela APA. Foram identificados 55 elementos constituintes da infraestrutura de apoio ao turismo, localizados em Serro e Santo Antônio do Itambé; e 140 equipamentos e serviços turísticos distribuídos em sua maioria também entre esses mesmos municípios. Esses locais se destacam em função de serem os municípios com maior percentual de área de abrangência da APA; pelo fato de Santo Antônio do Itambé possuir toda a sua área urbana inserida na APA; e em função de Serro possuir os distritos de Milho Verde, São Gonçalo do Rio das Pedras e Capivari no interior da UC, que são destinos turísticos importantes e apresentam maior quantidade de atrativos e serviços turísticos. Tais números podem ser visualizados no Quadro 2, abaixo. 
Quadro 2 - Elementos constituintes da oferta turística da Apaeav.

\begin{tabular}{|l|c|c|c|c|}
\hline \multicolumn{1}{|c|}{ Município } & $\begin{array}{c}\text { Infraestrutura de } \\
\text { apoio ao turismo } \\
\text { (A1 a A7) }\end{array}$ & $\begin{array}{c}\text { Serviços e equipamentos } \\
\text { turísticos } \\
\text { (B1 a B7) }\end{array}$ & $\begin{array}{c}\text { Atrativos } \\
\text { turísticos } \\
\text { (C1 a C7) }\end{array}$ & $\begin{array}{c}\text { Total por } \\
\text { Município }\end{array}$ \\
\hline $\begin{array}{l}\text { Couto de Magalhães de } \\
\text { Minas }\end{array}$ & - & - & 5 & 5 \\
\hline Diamantina & - & - & 4 & 4 \\
\hline Felício dos Santos & - & - & 4 & 4 \\
\hline Rio Vermelho & - & 1 & 5 & 6 \\
\hline Santo Antônio do Itambé & 20 & 34 & 20 & 74 \\
\hline Serra Azul de Minas & - & - & 1 & 1 \\
\hline Serro & 35 & 105 & 58 & 198 \\
\hline TOTAL & 55 & 140 & 97 & 292 \\
\hline
\end{tabular}

Fonte: MOTTA et al. (2014).

Como a Apaeav se encontra predominantemente em área rural, há grande carência de infraestrutura, com exceção de Santo Antônio do Itambé, Milho Verde e São Gonçalo do Rio das Pedras que possuem escolas, bancos, postos de saúde, várias lojinhas de artesanato e outros tipos de serviços de apoio ao turismo. Notou-se também a falta de transporte regular interligando os municípios da Apaeav, falta de equipamentos de saúde e precárias condições das vias de acesso aos municípios, distritos e povoados presentes na APA. Assim, a carência de infraestrutura se torna um inibidor do desenvolvimento turístico da área.

No que se refere aos equipamentos e serviços turísticos, estes também estão concentrados em distritos do Serro e em Santo Antônio do Itambé, sendo possível identificar a falta de equipamentos no restante da APA. Destaca-se que, mesmo nesses locais, os serviços são muito simples, na maior parte das vezes as empresas são familiares e informais. Além disso, percebeu-se a ausência de guias de turismo especializados e a inexistência de roteiros formatados e comercializados para grande parte dos atrativos da UC, o que dificulta e/ou reduz a demanda de visitação aos atrativos.

Em relação à distribuição dos atrativos turísticos em seus tipos e subtipos, destaca-se que a APA apresenta 58\% deles relacionados a aspectos naturais, sendo esses atrativos também os que possuem maior qualidade, potencial turístico, singularidade, diferencial e capacidade de atração de fluxo turístico. Os atrativos culturais e eventos permanentes inventariados apresentam-se como oferta complementar para aqueles que já se encontram na região, enriquecendo a experiência do turista. Apesar da importância e beleza cênica dos atrativos naturais presentes na APA, percebeu-se que eles estão pouco ou nada estruturados. As trilhas e estradas de acesso estão malconservadas, e percebeu-se uma ausência de sinalização na maioria dos atrativos.

Apesar de alguns entraves ao desenvolvimento da atividade turística, em função da precariedade dos elementos constituintes da oferta turística da Apaeav, destacam-se os distritos de Serro, em especial, Milho Verde, São Gonçalo do Rio das Pedras e Capivari, além do município de Santo Antônio do Itambé, que apresentam mais infraestrutura e equipamentos e serviços turísticos do que os demais. Nesses locais, os atrativos se encontram mais bem estruturados, com devida sinalização e alguns guias de turismo. Percebeu-se, também, uma preocupação com o patrimônio histórico cultural, nos quais possuem eventos programados, visando sua valorização e conservação. 


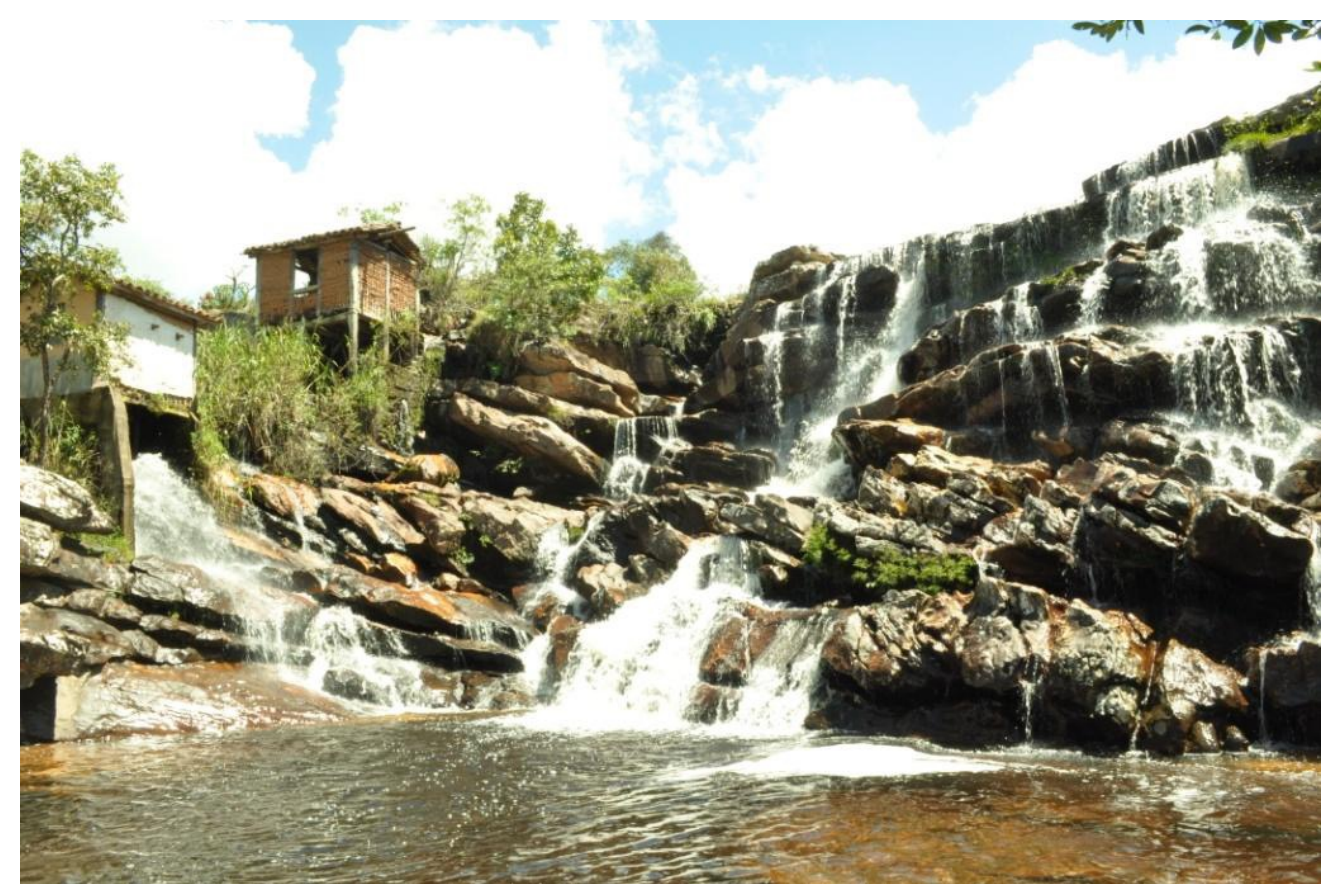

Figura 3 - Foto da Cachoeira do Moinho - Milho Verde Fonte: Acervo das autoras.

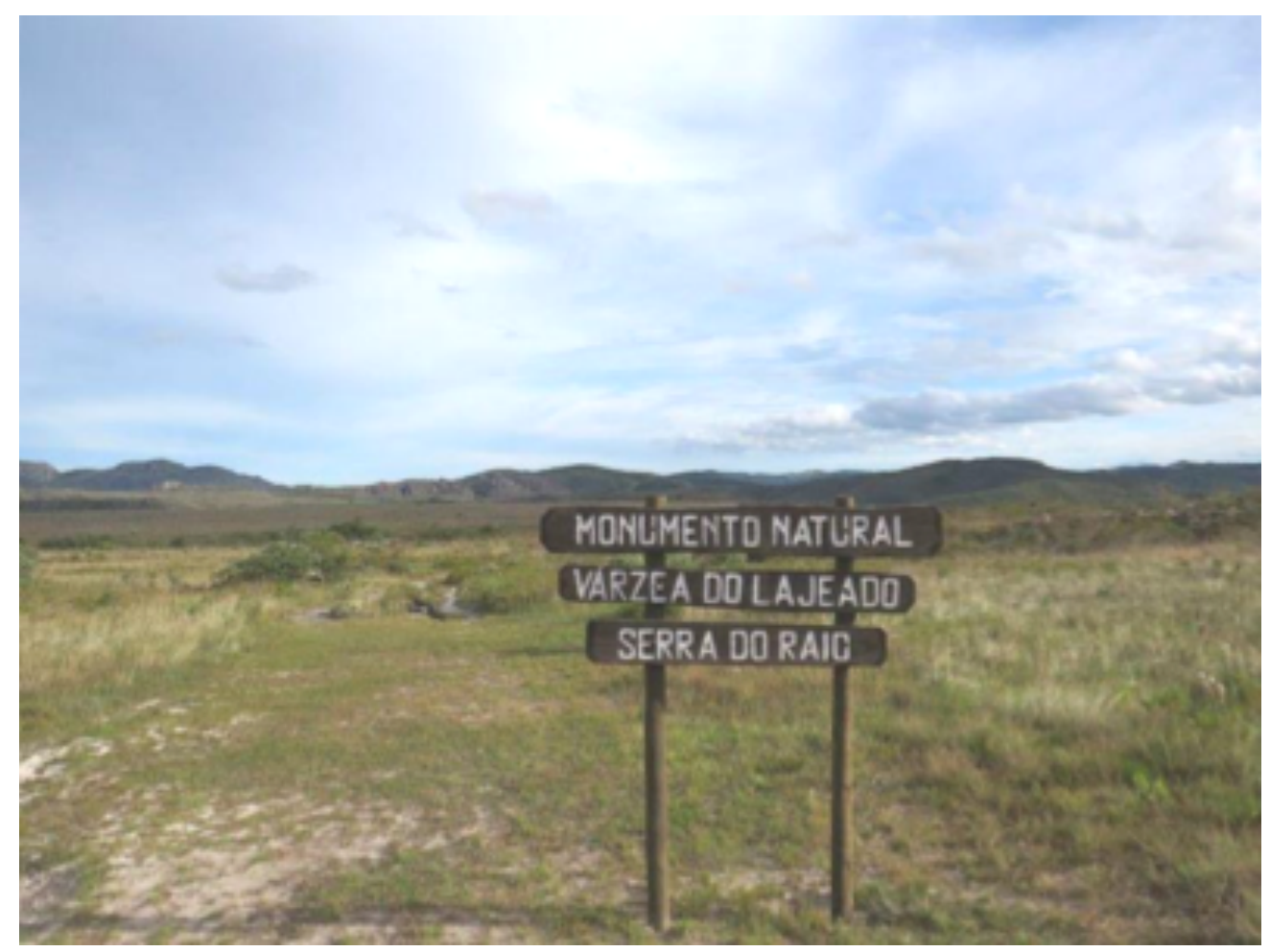

Figura 4 - Foto do Monumento Natural Várzea do Lajeado e Serra do Raio - Milho Verde. Fonte: Acervo das autoras. 


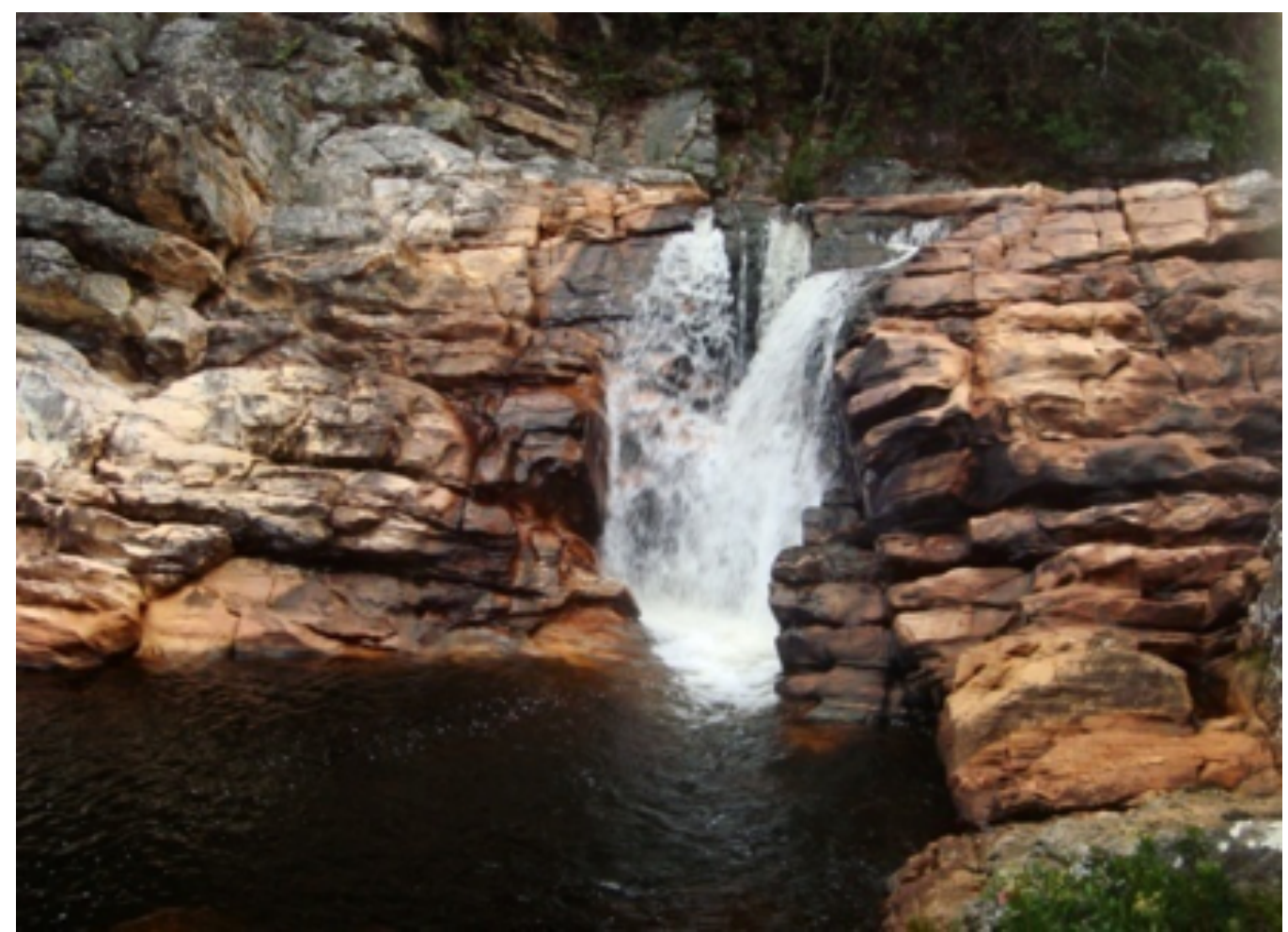

Figura 5 - Foto da Cachoeira do Cadete - São Gonçalo do Rio das Pedras Fonte: Acervo das autoras.

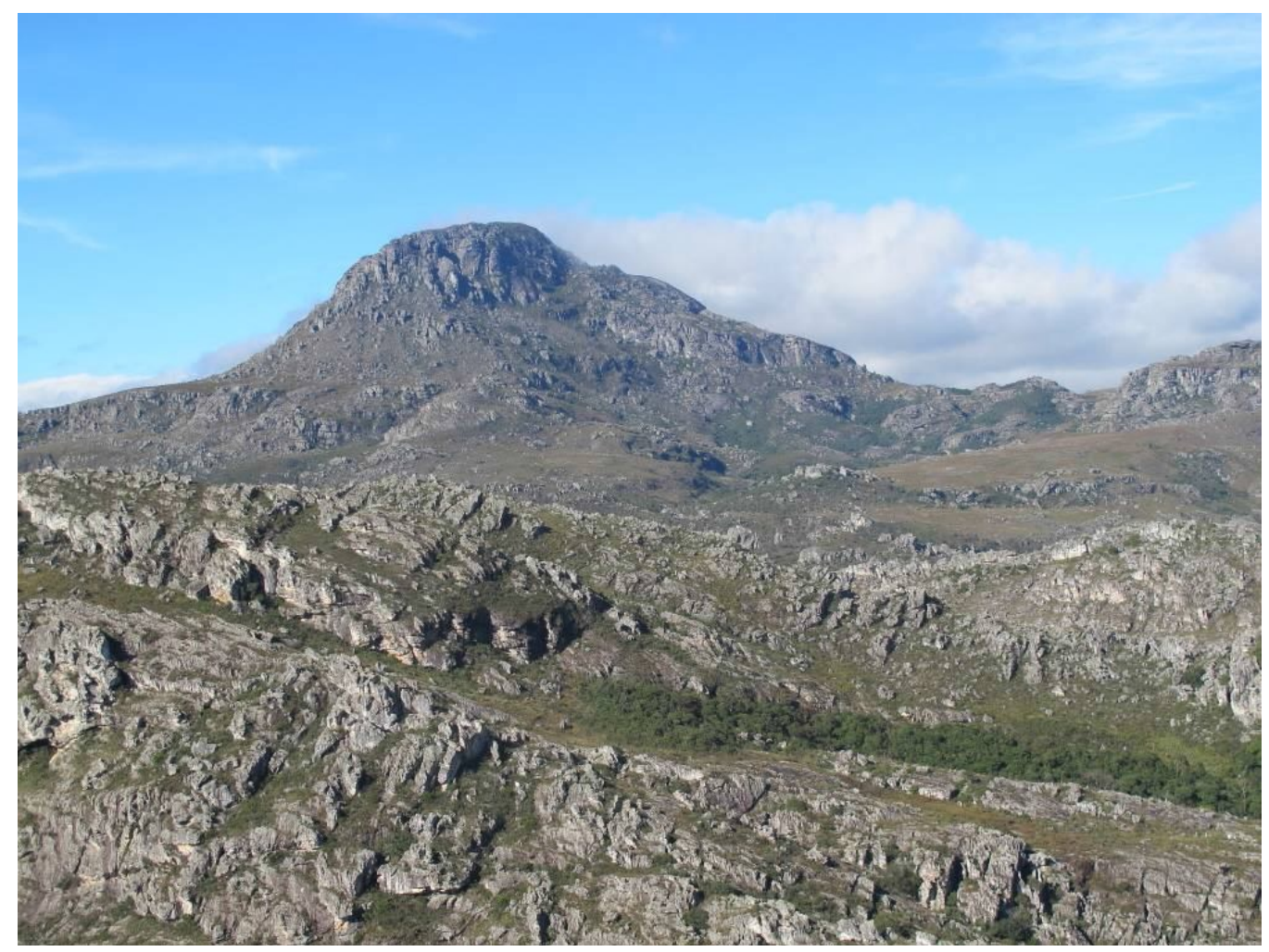

Figura 6 - Foto do Pico do Itambé - Santo Antônio do Itambé.

Fonte: Acervo das autoras. 


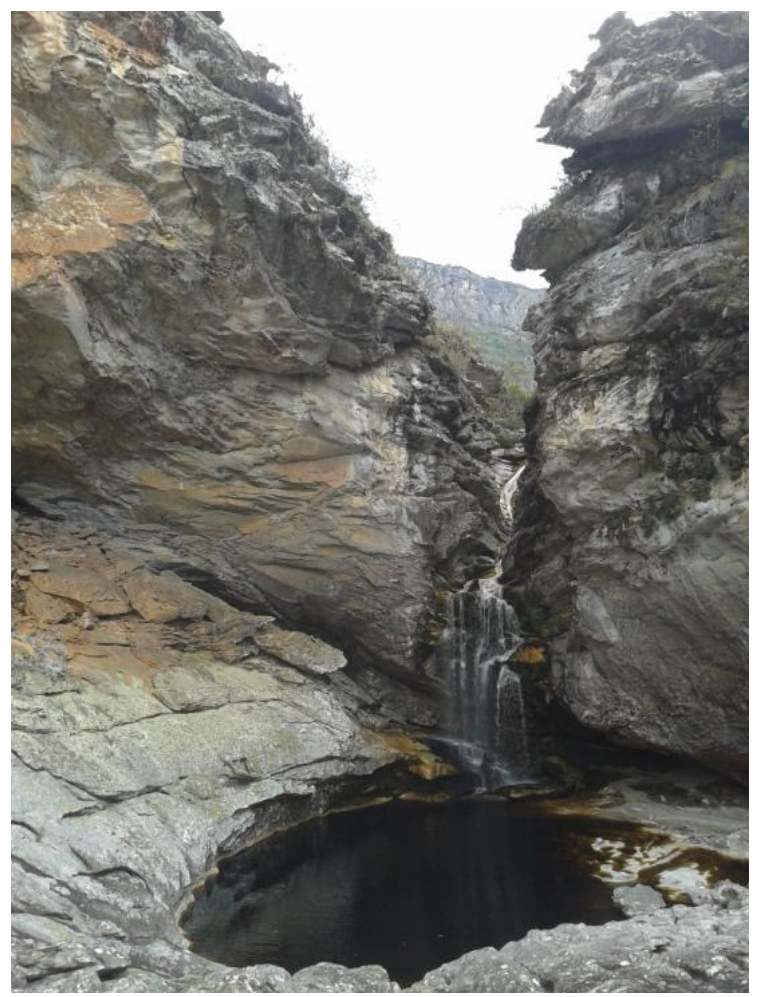

Figura 7 - Foto da Cachoeira da Cortina - Serro Fonte: Acervo das autoras.

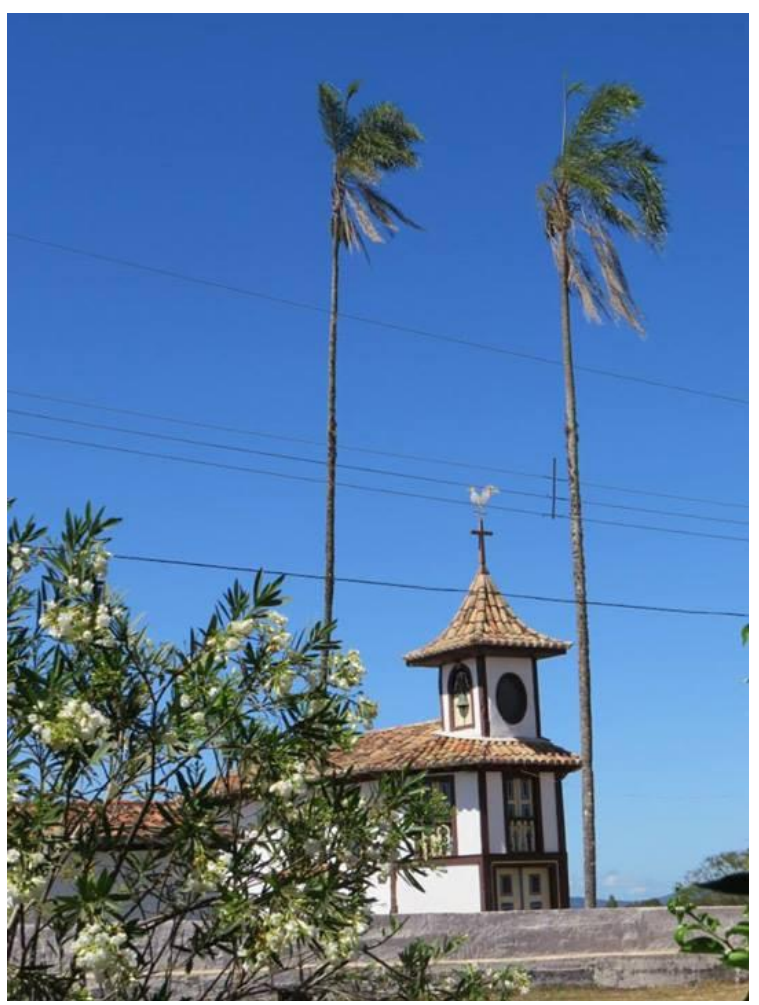

Figura 8 - Foto da Igreja de Nossa Senhora do Rosário - Milho Verde. Fonte: Acervo das autoras. 


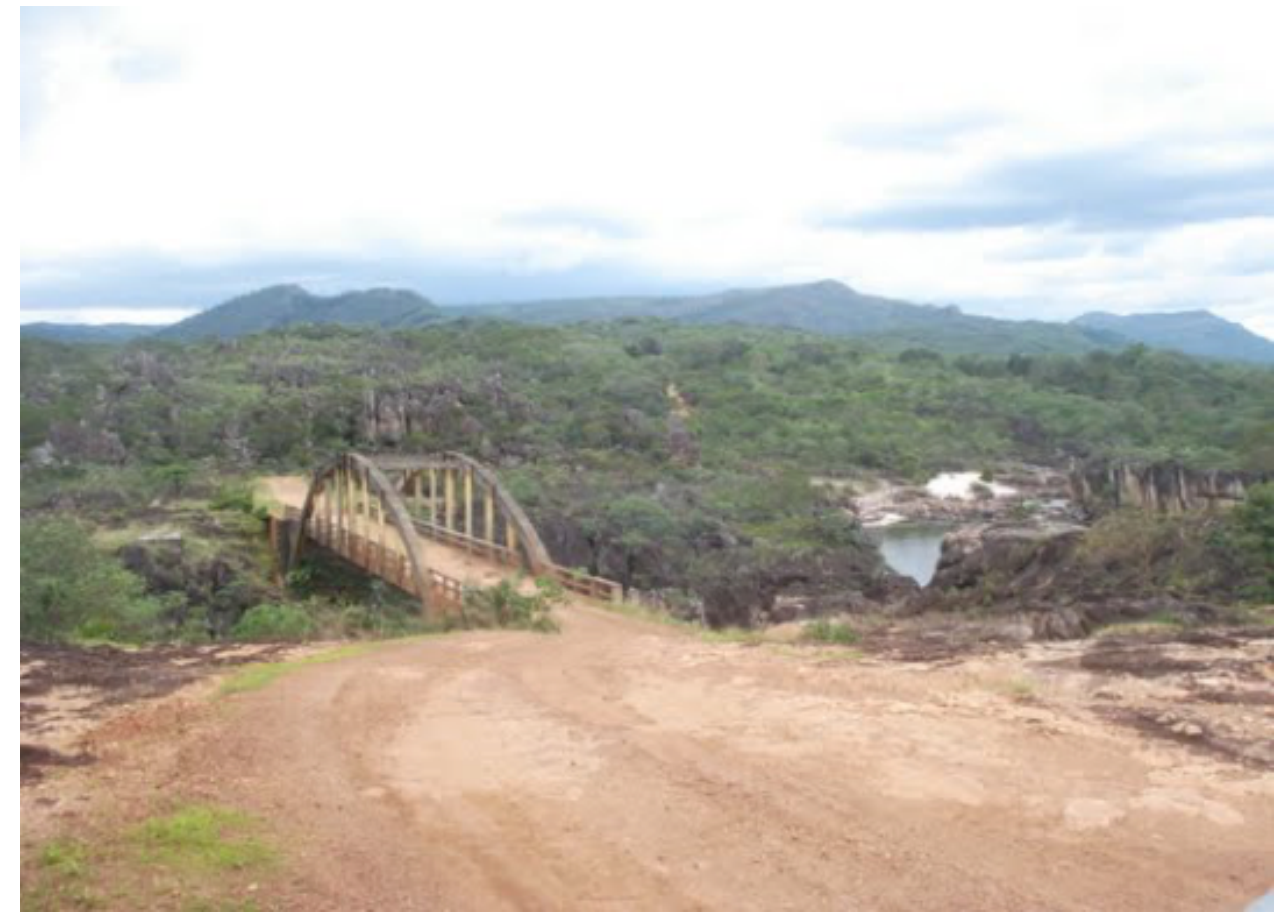

Figura 9 - Foto da Ponte do Acaba Mundo - Diamantina

Fonte: Acervo das autoras.

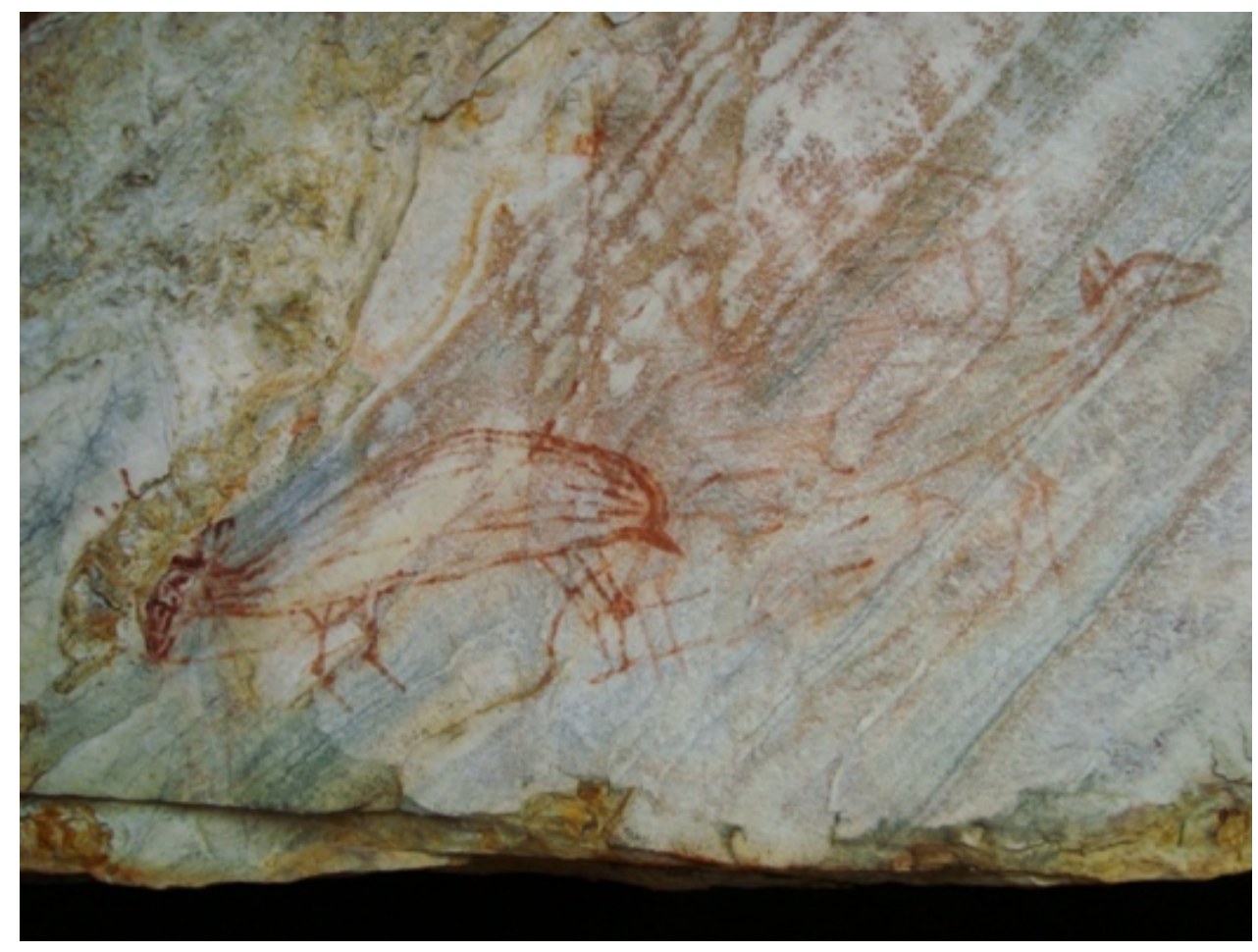

Figura 10 - Foto das Pinturas Rupestres da Serra do Raio - São Gonçalo do Rio das Pedras Fonte: Acervo das autoras. 


\section{GARGALOS, POTENCIALIDADES E DESAFIOS PARA A GESTÃO E PARA 0 DESENVOLVIMENTO DO TURISMO NA UC}

Por meio das pesquisas realizadas foi possível perceber um grande desconhecimento por parte de moradores, dos órgãos públicos locais e pela própria gestão da UC sobre o real potencial turístico da Apaeav e de como o turismo pode ser uma alternativa de geração de emprego e renda. Assim, a divulgação dos resultados da presente pesquisa para a comunidade, para o poder público e para a iniciativa privada é de fundamental importância.

Entende-se que os fatores que contribuem para a limitação na divulgação da UC são os mesmos que dificultam o estabelecimento de projetos bem estruturados e consolidados para o desenvolvimento do turismo na região: número reduzido de funcionários, recursos limitados, inexistência do Plano de Manejo e de outras pesquisas que contribuam para a gestão da UC.

No que se refere ao desenvolvimento do turismo na APA, entende-se que apesar do seu potencial turístico, existe um grande gargalo ao seu desenvolvimento de forma integrada, dada a grande extensão da UC, a escassez de infraestrutura e dificuldades e/ou inexistência de vias de acesso interligando toda a Unidade de Conservação. Assim, o desafio está no desenvolvimento de polos ou regiões onde a atividade possa acontecer, por meio da formatação de roteiros turísticos e travessias que integrem atrativos próximos e, ao mesmo tempo, incentivem o turista a realizar outros roteiros no interior da Unidade de Conservação.

A análise dos relatórios demonstrou que, em geral, são desenvolvidas as mesmas ações e projetos em toda a Unidade de Conservação. Souza (2014) aponta que é necessário se pensar em áreas com características socioambientais semelhantes na Apaeav, onde projetos similares devam ser desenvolvidos. E, por outro lado, considerar que alguns projetos são interessantes para determinadas partes da Apaeav, mas não são compatíveis com outras comunidades. Nesse sentido, também para o desenvolvimento da atividade turística, percebe-se que se deve procurar identificar a partir das pesquisas já realizadas inclusive o Inventário da Oferta Turística da Apaeav - quais as demandas de projetos de planejamento e ordenamento da atividade turística para cada região da Apaeav. Esse zoneamento de ações é importante, pois possibilita a realização de projetos compatíveis com a realidade de cada região da UC.

A estruturação e manutenção de trilhas com a devida sinalização dos atrativos turísticos também são necessidades prementes e podem ser sanadas por meio de parceria entre os gestores da Apaeav e as comunidades para a elaboração de placas. A sinalização com placas de madeira já é utilizada em várias localidades e atrativos da APA e poderia ser expandida para o restante da área.

Outro desafio é o incentivo à criação e/ou melhoria de serviços e equipamentos turísticos e capacitação de mão de obra. Essa questão relacionada à capacitação deve ser realizada tendo como base dois eixos de atuação. O primeiro eixo seria para aqueles locais que já possuem um fluxo turístico, com oferta de cursos voltados para a melhoria dos serviços daqueles que já trabalham com o turismo. O segundo eixo seria voltado para as regiões que possuem potencial turístico e ausência de serviços turísticos, com oferta de cursos para aqueles que gostariam de trabalhar com o turismo, mas não sabem como fazê-lo.

Há que se pensar também em parceria com operadoras turísticas (Serra Sertão, Veredas do Espinhaço e Andarilhos da Luz) e Universidades (UFMG e UFVJM) que emitem turistas/estudantes para as localidades pertencentes à Apaeav, como forma de geração de fluxo turístico intencional e que viabilizem a sustentabilidade da atividade turística na unidade, proporcionando geração de emprego e complementação da renda para as famílias que comecem a trabalhar com o turismo. 
Além disso, é necessário reconhecer a importância dos segmentos de turismo que envolvem a visitação a atrativos naturais, tendo em vista que foi identificado que esse é o maior potencial da unidade. Porém, não diz respeito somente ao ecoturismo, como referenciado no decreto de criação da unidade. Há que se considerar outros segmentos, como turismo de aventura, turismo rural, cultural, etc.

\section{CONSIDERAÇÕES FINAIS}

A presente proposta alcançou o objetivo de realizar uma análise do panorama do turismo e da gestão da Apaeav por meio da compilação de dados das duas pesquisas realizadas na Unidade de Conservação por membros do Gipe. Considera-se que as metodologias propostas foram satisfatórias para o alcance do objetivo, sendo pertinente a realização dessas análises em outras UCs. A análise dos documentos de gestão demonstra a atual situação da unidade, a partir da relação entre o que foi proposto e as ações executadas pela gestão. Por outro lado, a inventariação da oferta turística da Apaeav espacializa o potencial da UC, e, portanto, é essencial para o planejamento do turismo na APA.

Considera-se importante que se busque a ação coletiva e integrada para o desenvolvimento sustentável do turismo na Apaeav. Esse modelo de gestão deve levar em consideração as características de cada área da UC, sendo necessário traçar metas estratégicas de acordo com a realidade observada. Nesse sentido, o zoneamento da APA, que está sendo elaborado com seu Plano de Manejo, será muito interessante, pois fornecerá dados mais aprofundados sobre cada área da unidade. Porém, mesmo sem esse documento, é possível realizar um Plano de Ação de Turismo estratégico a partir das presentes pesquisas realizadas na UC, considerando a diferença entre os locais onde o turismo já é mais estruturado e existe uma demanda efetiva; e os outros locais, onde há um enorme potencial para a atividade, porém, nem mesmo os moradores têm consciência das possibilidades de desenvolvimento do turismo. Busca-se, assim, atender à realidade local e não somente realizar a reprodução de ações pontuais em cada comunidade.

Ressalta-se o enorme campo de pesquisa ainda não explorado na Apaeav, especialmente nas ciências humanas. Cabe destacar, ainda, que os estudos fruto deste artigo foram pioneiros na busca ao atendimento das demandas da própria gestão da UC, pois foram consolidadas a partir do alinhamento entre os pesquisadores e o órgão gestor da Apaeav. Esse tipo de parceria é importante para sanar a carência de documentos, pesquisas e informações sobre a UC, por sua vez, fruto da escassez de recurso humano e financeiro para execução de muitas ações e pesquisas em UCs. Dessa forma, entende-se que a continuidade de pesquisas na Unidade de Conservação, que complementem os estudos já realizados, é de suma importância para contribuir para o desenvolvimento do turismo na região e para o alcance dos objetivos de criação da APA das Águas Vertentes.

\section{REFERÊNCIAS}

ABREU, P. A. A.; FRAGA, L. M. S.; NEVES, S. de C. Geologia. In: SILVA, A. C.; PEDREIRA, L. C. V. S. F.; ABREU, P. Â. A. (Ed.). Serra do Espinhaço Meridional: paisagens e ambientes. 0 Lutador. Belo Horizonte, 2005.

ÁVILA, G. C. de. Mosaico de áreas protegidas do Espinhaço: alto Jequitinhonha e Serra do Cabral, Minas Gerais e os desafios para sua efetividade. Dissertação (Mestrado) - Instituto de Geociências UFMG. Belo Horizonte, 2014. 
BENI, M. C. Política e Planejamento de Turismo no Brasil. São Paulo: Aleph, 2006.

BRASIL. Lei $\mathbf{n}^{\circ} \mathbf{9 . 9 8 5}$, de 18 de julho de 2000. Regulamenta 0 art. 225, parágrafo $1^{\circ}$, incisos I, II, III e VII, da Constituição Federal, institui o Sistema Nacional de Unidades de Conservação e dá outras providências. Brasília, 2000.

BRASIL. Ministério do Turismo. Projeto Inventário da Oferta Turística: manual do pesquisador. Brasília, 2006.

BRASIL. Ministério do Turismo. Ecoturismo: orientações básicas. Ministério do Turismo, Secretaria Nacional de Políticas de Turismo, Departamento de Estruturação, Articulação e Ordenamento Turístico, Coordenação-Geral de Segmentação. 2. ed. - Brasília: Ministério do Turismo, 2010.

CABRAL, N. R. A. J.; SOUZA, M. P. Área de Proteção Ambiental: planejamento e gestão de paisagens protegidas. São Carlos: Rima, 2005.

DIAS, R. Introdução ao Turismo. São Paulo: Atlas, 2005.

FERNANDES, T. B. et al. Relatório Anual de Atividades da Área de Proteção Ambiental Estadual das Águas Vertentes. Instituto Estadual de Florestas. Diamantina, 2014.

FONTOURA, L. M.; SILVEIRA, M. A. T. da. Turismo em Unidades de Conservação e Planejamento Territorial: um foco no Parque Estadual de Vila Velha/PR. In: V SEMINÁRIO DE PESQUISA EM TURISMO DO MERCOSUL. Caxias do Sul, 27 e 28 de jun. 2008.

FRAGA, L. M. S.; ABREU, P. A. A.; NEVES, S. de C. Hidrologia e Hidrografia. In: SILVA, A. C.; PEDREIRA, L. C. V. S. F.; ABREU, P. A. A. (Ed.). Serra do Espinhaço Meridional: paisagens e ambientes. 0 Lutador. Belo Horizonte, 2005.

GIL, A. C. Métodos e Técnicas da Pesquisa Social. 4. ed. São Paulo: Atlas, 1994.

GONTIJO, B. M. Uma Geografia para a cadeia do Espinhaço. In: Conservação Internacional/Brasil. Megadiversidade - Cadeia do Espinhaço: avaliação do conhecimento científico e prioridades de conservação. v. 4, n. 1-2, dezembro de 2008.

LAKATOS, E. M.; MARCONI, M. de A. Metodologia Científica. 5. ed. São Paulo: Atlas, 2007.

MINAS GERAIS. Decreto no 39.399, de 21 de janeiro de 1998. Dispõe sobre a criação da Área de Proteção Ambiental - APA no Estado de Minas Gerais e dá outras providências. Publicação - Diário do Executivo: Minas Gerais, 22 jan.1988. Disponível em: http://www.siam.mg.gov.br/sla/download. pdf?idNorma=1491. Acesso em: 07 mai. 2014.

MOTTA, A. I. R. da. et al. Análise da Oferta Turística da APA Estadual das Águas Vertentes. Relatório de Bolsa de Iniciação Científica. UFVJM. Diamantina, 2014.

SCALCO, R. F. Desafios, paradoxos e complexidade na gestão do Mosaico de Unidades de Conservação da Área de Proteção Ambiental Cachoeira das Andorinhas - Ouro Preto/MG. Dissertação (Mestrado) - Instituto de Geociências da UFMG. Belo Horizonte, 2009.

SOUZA, D. E. de. Relatório Anual de Atividades da Área de Proteção Ambiental Estadual das Águas Vertentes. Instituto Estadual de Florestas. Diamantina, 2013.

Aspectos Socioambientais e a Gestão da APA Estadual das Águas Vertentes. Dissertação (Mestrado) - Instituto de Geociências - UFMG. Belo Horizonte, 2014. 